\title{
Contemporary Cambodian Dance and Sites of National Culture: Chumvan Sodhachivy's YouTube Page
}

This chapter traces the relationship between contemporary Cambodian dance and the constitution of national culture. It examines filmed dance performances and screendances created by the contemporary Cambodian dancer, Chumvan Sodhachivy (Belle), and her troupe 'Silver Bell', that are regularly uploaded onto her YouTube page.' Analysing these filmed and filmic works highlights the varied sites of dance practice among professional contemporary dancers in Cambodia, and the role of practitioners in reproducing and re-constituting national culture. Artistic practices can promote a new image of Cambodia, with dancers reworking elite practices in response to the sensibilities of young Cambodians and social issues. Belle's YouTube page reflects a global, outgoing perspective that cuts across everyday and state-led realms of (national) culture, displaying different modes of expression across sites that range from disused buildings, to beaches, casinos and foreign cultural institutes.

Through this discussion, the chapter contributes to an emerging body of work that investigates the relationship between creative practice and (geo)political phenomena (Ingram 2011; Kuhlke 2014; Militz and Schurr 2016). Specifically, it develops research examining the intersections between performance and nationality (Plancke 2016; Cronin and Till 2017; Rogers 2018) by attending to how dancers create emergent forms of national culture as they traverse different locations: commercial sites; NGOs and global cultural circuits; and everyday Cambodian landscapes. In so doing, the chapter highlights that the nation is a performed entity, but its importance fluctuates in prominence and intensity.

\section{Nation, Culture and Creativity}

The nation is the pre-eminent form of political organisation, being conventionally defined as a human population that 'shares myths and memories, a mass public culture, a designated homeland, economic unity and equal rights and duties for all members' (Smith 1995, 56-57). However, research has highlighted how the nation is not a pre-given, naturally existing phenomena (Weber 1998; Edensor 2002) but an emergent 'category of practice' through which the world is ordered (Brubaker 1996, 21). Performative metaphors have emphasised that the nation is contingent and constantly in process (Jones and Merriman 2009, McConnell 2016), with recent geographical research exploring how the arts expose contestations around territory, the constitution of post-conflict world orders, and assumptions around the production of national culture (Ingram 2009; Pinkerton and Benwell 2014; Rogers 2018). The imaginative potential of the arts therefore makes them fertile ground for interrogating and reconstructing spaces of nationality, particularly through the body (see Mayer 2004 more broadly). 
Research in anthropology and dance/performance studies has long investigated the interchange between dance and nationality, analysing how dance produces 'embodied communities' (Hughes-Freeland 2008) that are often also intersectional or highly gendered (Shapiro-Phim 2008). Research has also examined the tense, contradictory relationship between dance and national cultural heritage (TuchmanRosta 2018), and the transformations that result when dance is inserted into circuits of globalisation (Reed 2010, Plancke 2017). For Plancke (2016, 151), dance is a "strong symbol for making identities", particularly at the national level, as individuals and communities seek to differentiate themselves amid the flux and uncertainty of globalization. Interdisciplinary dialogues between dance studies and geography can develop these discussions through an attention to questions of spatiality whilst also building on geographical concerns that there is much more to be said about the nation's aesthetics' beyond conventional material artefacts and iconographies (Closs Stephens 2014, 62). The tension between presence and absence, documentation and ephemerality that characterises performing arts praxis points towards how we might think through the shifting 'tonalities and intensities of nationality' (ibid.), to when - and where - performances of nationality come to matter.

Implicit in these discussions is that national cultures and creative processes are both protean. As Richardson (2017) has argued, culture and creativity are often synonymous in cultural geography, despite the multiple and overlapping theoretical lineages of each term. This multiplicity can be a strength, a way of thinking through the possible work that creative practice can do and the kinds of worlds or cultures it might create (Hawkins 2017). Here, I similarly hold the plural relationship between creativity and culture in tension because contemporary Cambodian dancers traverse sites of praxis that differently configure the (re)production of national culture through the performing body. As a cultural-creative practice, dance can operate as a form of innovation that produces easily consumable products in the context of commercial globalisation (Liep 2001). However, Belle's contemporary dances reflect an on-going creative process that continues and extends existing cultural formations, multiplying their meanings and values (Ingold and Hallam 2007).

When thinking through these dynamics in relation to national culture, contemporary Cambodian dancers bridge elite and everyday spaces of nationalism. Traditionally, research on nationalism has fallen into two camps. Firstly, there has been a focus on 'high' cultural forms such as ceremonies or pageants; eventful activities that iconographically represent state-sanctioned ideologies (Hobsbawm and Ranger 1983). Secondly, research has examined popular, everyday forms of national culture that go unremarked or unnoticed (Billig 1995). Edensor (2002) argues that the latter are more politically ambiguous, a site of greater cultural dynamism or contestation than the former. However, studies of nationality in geography are starting to muddy these divisions. For instance, Antonsich (2016) argues that attending to what and where 
constitutes the 'everyday' brings state-centric reproductions of the nation into dialogue with those occurring in everyday sites of activity.

This chapter contributes to these debates because contemporary dancers traverse different realms. Professional dancing bodies in Cambodia are predetermined as national bodies owing to their historical associations with the state and the Royal Family, as well as their institutional training in traditional dance forms at the Secondary School of Fine Arts (SSFA) and the Royal University of Fine Arts (RUFA). Many (but not all) contemporary dancers work as dance teachers in the state education system, teaching traditional dance forms in the morning before experimenting with movement vocabularies and developing modes of expression elsewhere in the afternoons and evenings. All professional dancers in Cambodia are part of elite national culture, including those working in a contemporary vein, and all can perform dances associated with that realm. However, some also create movement vocabularies that adapt traditional performance vocabularies, using these to express everyday concerns such as environmental pollution on the streets of Phnom Penh, social expectations of women, or the need for education. This blurring features in the lives of many contemporary dancers. Belle's YouTube page highlights the varied spaces through which these different modalities of 'contemporary Cambodian dance' emerge and their fluctuating relationship to nationality.

\section{Methodology}

Geographers are increasingly undertaking online research, particularly using social media sites such as YouTube (Longhurst 2009, Laurier 2015). The internet is a source of empirical information and a research location that places 'virtual' and 'real' spaces on a shifting continuum. YouTube is a 'site of dynamic and emergent relations between market and non-market, social and economic activity' with its variety of producers, audiences and interests marking it out as a unique site (Burgess and Green 2009, 90). This growing interest in online research coincides with increased experimentation with videographic methods to explore and capture embodied spacetimes (Simpson 2011). Video is often incorporated into a broader ethnographic toolkit whereby methods are combined and used in innovative ways. For instance, Veal's (2016) geographical articulation of a choreographic notebook incorporates videography alongside diagrammatic notation (such as Labanotation), movement description, photographic representation, sketching, and interviews.

Film has long been used to capture the movement, rhythm, affective qualities and social contexts of dance (Hughes-Freeland 1999). Nevertheless, dance studies is grappling with how to analyse screendance, where dances are filmed to be watched on screen, rather than live. As screens become more prolific in society, screendance changes the composition and form of dance because the dancing body seems to no longer be elusive or immediate (Rosenberg 2012). Instead, the body is co-produced 
through lighting and the technological manipulation of distance (the close up), duration (editing), and spatiality (the frame) (Somdahl Sands and Adams 2014; Norman 2010).

Belle's YouTube page contains 84 videos at the time of writing, uploaded over seven years, though some are older. They range in length from under a minute to over fifteen, and are diverse in content, technological quality and stylistic approach. The majority are films or recordings of dance, rather than dance films or screendance. They are often documents of live performances recorded from a conventional audience perspective, straight on or slightly to one side. The films have variable viewing figures, with some being viewed a handful of times, and others hundreds of times. Her commercial performances are often the most viewed, which perhaps reflects how Belle uses these to 'show what you have done before. Then you can see on my video, on my phone.' However, some dances created in artistic settings also have high viewing figures. Much of the existing work on YouTube dance videos is based around a single genre (see Peters and Seier 2009 on home dance). Here, I focus on a single practitioner, using YouTube as an autobiographical archive that documents both their movement history and how it cuts across genres and spaces, extending research that examines how this platform stages the self. Belle insisted that 'I do not have a professional "this is my website of contemporary dance"; I just put it up and keep for myself as a document.' As such, her YouTube page was used for publicity, personal inspiration, reflection, remembering, and as an archive of her praxis.

Following mixed-methodology approaches, I use video analysis alongside interviews conducted with Belle in Phnom Penh in 2014 and 2018, and my own experience in learning and performing various dance forms. Specifically, I undertake a conventional form of image-based content analysis that categorises the type or genre of dance performed (commercial, screendance, artistic/NGO, other) whilst also attending to the location of filming. Indeed, a dance's choreography and form usually responds to the site of performance. In using dance ethnography, I also examine 'narrative, iconographic gestures, symbolic images, social relationships in choreography, but also [. . .] how meaning is literally embodied in the dancer's physicality, in the phenomenological realities of weight, space and movement intentionality' (Albright 1997, 50). There are limitations to this approach in terms of capturing experience and feeling, but observational techniques can convey the expressiveness of the performing body (Rogers 2012, Veal 2016). For screendances, issues of editing and screen spatiality are paid greater attention.

\section{Dance and Nationality in Cambodia}

First, I provide a brief overview on classical and contemporary dance in Cambodia and illustrate how dancers such as Belle traverse multiple sites of praxis. Dance is synonymous with Cambodian national identity, being 'essential to the perpetuation of Cambodia as a cultural and political entity' (Phim and Thompson 1999, 
2). Classical dance has been performed for the king since at least the $9^{\text {th }}$ century, but in the 1940s it was overtly linked to the state-led promotion of national identity, when dancers accompanied King Norodom Sihanouk on diplomatic tours. Under the Khmer Rouge (1975-1979), 90\% of dancers were executed owing to their elite associations, and much of the post-genocide era has focused on restoring Cambodia's dance heritage. In the process, the relationship between dance and nationality has intensified such that nationality has become a 'unique weight [for dancers] to bear' (Shapiro-Phim 2008, 63).

However, younger dancers can have a slightly different relationship to their cultural heritage as they have an outward-looking, cosmopolitan perspective. Some arts NGOs have responded to this, facilitating international residencies and collaborations with contemporary dancers from Europe, North America and Asia. In Cambodia training in contemporary dance is limited and only began in 2017-18 at RUFA. A 'professional' dancer has graduated from RUFA in dance or choreography, with students training since childhood in a specific traditional dance form (classical dance, folk dance, lakhon khol or shadow theatre). Classical dance comprises 4 roles (male, female, giant, monkey) using over 4,500 hand gestures (kbach) that are combined with bodily postures. State educational settings therefore promulgate the reproduction of traditional dance and, by extension, its association with nationality (Eggert 2011). Professional dancers reproduce this association because after graduation one employment option is to work as a teacher at the SSFA or RUFA. Some dancers join the Ministry of Culture and Fine Arts' Department of Performing Arts, where dancers perform in the traditional repertoire (particularly on state visits) and undertake limited choreographic reconstruction.

Contemporary Cambodian dance takes two main forms. The first entails taking classical dance lexicons and re-choreographing them to tell existing stories from the Reamker (the Cambodian Ramayana) in new ways, to tell new stories about Cambodian life, or to explore expressive possibilities and ideas (see Shapiro 2010). Here, however, I focus on the second type, where traditional dances are integrated with various other genres such as hip hop, modern dance, ballet, and belly dancing. This process shifts the embodied physical motion and meaning of dance and has created concerns over the loss and degradation of traditional dance vocabularies. The historical embeddedness of dance in the reproduction, indeed rebuilding, of Cambodia, means that concerns over expression are also concerns over the constitution of nationality.

Belle's career reflects these dynamics. Born in 1986, she started learning classical female role aged 8 before being switched to male role because she grew too tall for the petite, delicate embodiment required for female role. Her training was therefore exclusively in a traditional dance form, but she felt restricted by its codified lexicon. In her teens she therefore began to explore other dance genres: 
I told my mum that I wanted to do something new. My mum brought me to a private dance club for lessons in the evening. The dance was pop dance, Michael Jackson, and aerobic because at that time he was very famous [. . .] When I study it, I can experiment with my body on how flexible I am to do the new movements that I never did before. I still study classical dance until I graduated. On the other hand, I research something new what is fitted with me.

Belle described a spatially segmented world: the strictures of classical dance in educational settings; and the different, perhaps more freeing, routes for personal expression found outside these realms. This division was mapped onto spaces of nationalism and cultural globalization, and it persists today. Dancers described teaching at school in a strict fashion in order to perpetuate national cultural traditions, including Belle, who was adamant that 'it is our root. You cannot do anything besides what teacher tells you. [. . .] Students should know the difference, you must respect the tradition, you cannot change the movements. [. . .] This is our culture, our identity.' However, international arts NGOs and cultural institutes are key sites for dancers developing contemporary dance styles, and have helped legitimise this genre in Cambodia. Cambodian arts NGOs therefore enable dancers to explore different dance forms vis-à-vis cultural globalization, although Belle also mentioned using the internet to watch contemporary dance. Dancers also establish peer networks and friendships in order to explore and develop contemporary dance possibilities.

This chapter highlights how Belle's contemporary dance practice illustrates that cultural forms can be developed in ways that do not pose an opposition between a static, elite form of national identity and a fluid globalization that erodes national attachments. Rather, there are "innumerable pathways, connections and sources" between the two (Edensor 2002, 33). For instance, when discussing watching contemporary dance from abroad, she described how:

When you watch [. . .] contemporary performance of foreigners, it is their own idea and style, but we have to see it as another world. For our world, we have to work with our people also to discuss about our own problem, happiness, and idea. We need our original idea, Khmer idea, from us.

Here, Belle implicitly challenged common accusations that contemporary dance in Cambodia is copying, and that it undermines traditional (national) dance forms. One reason why she liked contemporary dance as a genre was that it could 'connect with daily living', creating discussion about different ideas and perspectives so that 'you understand what your idea means, how it relates [to society], and what dances you want to create.' The cosmopolitan attitude of openness fostered by learning dance genres from abroad extended to Cambodian society at home, such that contemporary dance can help explore everyday worlds and their links to national cultures, rather than 
assuming that the traditional, particularly classical, dancing body is the sole arbiter of national culture. When Belle's teacher questioned her commitment to her national culture (as embodied in dance) she responded:

I said to her, 'Do you know the reason I do contemporary dance? It is also because I love classical dance. I love my culture. I want to develop it. The way I want to develop it is by taking contemporary dance style.'

Here, Belle's understanding of Cambodian culture is aligned with ideas of creativity as continuous adaptation and change (Ingold and Hallam 2007). Developing contemporary Cambodian dance as a genre was also a marker of pride in being a developed country and in 'being Cambodian'. The different ways that dance articulated the interplay between culture, creativity and national identity were therefore not seen by Belle (or indeed by other contemporary dancers) as incompatible; rather they coexisted.

\section{Contemporary Dance and Commercial Sites of Performance}

Discussing these dynamics prevents a simplistic reading of the videos on Belle's YouTube page, particularly those in a commercial vein (which at 42 videos constitute the largest group). Commercial dances are choreographed either for the tourist or entertainment market, or for company events and product launches. These sites render Cambodia's insertion into globalisation obvious by engaging with cultural difference vis-à-vis the dancing body. These dances are easily consumable set pieces at around five to six minutes. The dance on display is of two types: forms of contemporary dance that emerge in Cambodia through circuits of cultural globalisation without referencing traditional Cambodian forms, what Belle called a 'fusion' style; and those that gesturally reference traditional Cambodian forms, but mixes these with other genres. Belle created her dance troupe 'Silver Bell' explicitly for commercial work as friends started to ask her to create dances for their workplaces. This became a way of earning money because professional dancers are paid very little, with teachers sometimes not earning enough to cover their travel costs to work, making multiple jobs necessary (see Tuchman-Rosta 2018 for more on the economy of Cambodian dance). However, Belle described her increased selectiveness around the commercial work she undertook as she became older, recommending others to choreograph certain events, and considering the values attached to projects or products rather than simply earning money:

When I was young I did create dance for beer companies and cigarette companies, but right now it's not what I want. What is going to happen to the people that are smoking? We need money but we need value also. It's a personal thing. But if 
it is about babies, the meal for old people to support the bone, the memory, the health, ok, I'm interested.

These negotiations around economic capital coincides with a recent increased emphasis on her page towards choreographic work, to making pieces that other dancers then perform (see below) and to showing dances in rehearsal. With age comes increased responsibility towards cultural values in Cambodia, particularly for women, alongside increased tolls on the body, focusing attention on her choreographic, not only dancing, abilities. In turn, this changes the relationship between her own dancing body and its production of economic value.

Dances performed in entertainment settings such as NagaWorld use a 'fusion' style, combining salsa, samba, Egyptian belly dancing undulations, hip hop or American pop music and movement, performed in triangular or linear formations that characterise western pop dancing (rather than the 'figure 8' movement-spaces of classical dance). These routines are spectacular, designed to elicit entertainment and excitement through culturally 'exotic' references, particularly as they use glittery costumes and incorporate showpiece movements (such as firebird jumps from western ballet, or high lifts). Specific movements and gestural imagery create spectacles that induce affective experience in ways that divorce dances from their historical, cultural and national contexts. Plancke (2016) views this process as part of the capitalist commodification of dance, which is unsurprising in these settings. At business events or product launches, choreography is linked to the financial context of production, with dance used to make products appeal to particular markets, such as hip hop routines created to promote smart phones for young Cambodians (including Samsung), a dance based on office behaviours and western pop movements for a Colgate-Palmolive conference, or using jumps, reaches and straight extended limbs for an insurance company whose logo is a star.

Sometimes the encultured physicality of the Cambodian dancing body is utilised, such as in upturned toes, or in simple Cambodian kbach (notably the flexedback hand that signals a leaf, or the touching of forefinger and thumb with the remaining fingers extended and splayed that means a flower). The kbach are then combined with different dance vocabularies. For instance, the hands may use kbach but these may be performed at speed with angular hip hop arms, or they may move slowly but be performed with basic western ballet postures for the arms and legs ( $2^{\text {nd }}$, $4^{\text {th }}, 5^{\text {th }}$ position) or with belly dancing hip rolls, full body undulations and side steps. Classical Cambodian dance movements, particularly the distinctive stretching of the fingers in the kbach, thus become part of an international expressive toolkit that can be reconfigured depending on market demands. Indeed, Belle's ability to perform multiple dance genres, whilst also referencing Cambodian forms, clearly holds a 'glocalizing' appeal (Robertson 1995). However, references to national culture via kbach are usually gestural, reflecting the transformation of complex local traditions of 
performance into aestheticized events' (Reed 2010, 5; Rogers 2014). Nevertheless, these works reflect how Cambodian businesses and the country's young population want to be seen as a modern nation conversant in cultural globalisation.

It is commonplace to suggest that commercial settings signal the death of cultural performance forms, but commercialism also offers creative possibilities. Firstly, the commercial inclusion of traditional Cambodian dance can promote national cultural forms in a fun and far-reaching way, although Belle was aware that this was a doubleedged sword. She was concerned that young people who wanted to study with her thought that fusion or contemporary dance was classical Cambodian dance, so she told them to 'research more' before approaching her again. Nevertheless, these dances stimulated interest among young audiences who often know little about traditional culture (see also Grant 2016). Belle epitomises how dancers can engage with multiple genres and styles of movement in a cosmopolitan fashion whilst reinforcing respect for, and facility in, a mode of embodiment that represents specific national or cultural backgrounds (Pine 2014). Secondly, commercial sites provide money and technology to experiment with staging. In interview, Belle described how technical difficulties impacted on what contemporary Cambodian dance might become:

If you go abroad [. . .] New York City, their show is really amazing like the technique, costume, and lighting. When you come back here, it is different! [. . .] I want to create a piece, with my dancers here and the light here, but in Cambodia, we do not have the same lighting technology [. . .] Here, you do that by choosing another idea for creation on what we have. Candle lighting or torch! [. . . Y You have to think as a Khmer!

The limitations posed by Cambodia's creative infrastructure meant that deciding how to stage a work also makes it Cambodian. In a commercial arena such limitations are reduced. This is evident in a dance created for ISI Steel that uses hi-tech projections, with a lone male dancer dressed in silver performing a space battle sequence inspired by comic book action films. The dancer performs jumps and cartwheels with kneeling and fighting postures as he uses a steel shield to deflect laser targets. Such settings can therefore push the imaginative boundaries of contemporary dance creations.

\section{Contemporary Dance and the NGO sector}

In developing discussion about sites where Cambodian movement vocabularies and international dance genres intersect, arts NGOs are important. As I have discussed elsewhere (Rogers 2015, 2018), transnational and intercultural spaces are key to developing creative expression in the performing arts. In dance studies, Desmond (2017) similarly argues that cultural transmission and artistic transformation should be considered in relation to circulation and multi-sited re-creation. In Cambodia, international arts NGOs are sites where these spatialities are practically worked 
through, enabling dancers to develop contemporary expressions through cross-cultural embodied encounters. Of importance here is Belle's work with the NGO Amrita Performing Arts and performances sponsored or hosted by the Institut français du Cambodge (IFC). Not all of her dances created for these organisations are presented on her YouTube page owing to issues of copyright (such as Alphabet, a contemporary dance about the importance of education that uses Cambodian poetry and alphabetic recitations learned in school, that I witnessed Belle choreograph at the IFC in 2014).

Belle's choreographic style in dances created for NGOs is driven by creative, rather than commercial, interests. Although work in these sites is paid, it is more exploratory and developmentally driven. The Cambodian cultural references are greater with the dances often using movement vocabularies from classical dance or being grounded in 'Khmer ideas' and issues, even as they draw upon other international contemporary dance forms. This is where Belle's personal expression sits; it is in line with her perspective in interview and in the screendances discussed below. This setting provides a more refined sense of how cultural engagement works across multiple sites in the way that Desmond (2017) suggests. Indeed, Amrita and the IFC have facilitated sustained training for Cambodian dancers in different international contemporary dance genres, part of the process of developing, professionalizing and legitimizing contemporary Cambodian dance as a genre.

Belle's choreography can therefore be interpreted for how it criss-crosses multiple transnational spatialities, from the body, to the locale, to the nation, to international performance networks (see Rogers 2015, 2018). In the process, creative and cultural practices shift in their mode of enactment. These processes are displayed in a range of videos, such as a recording of a Cambodian television special that focuses on her career as a contemporary dancer, and that shows her performing several dances for national audiences, or her performance of Tiger Bell at a street dance event in Koh Pich (the 'diamond island' of Phnom Penh's waterfront) organised by the IFC. There is also an excerpt of Cello II, part of a series of dances Belle choreographed for Amrita in 2013 using Bach's Cello Suites. The series explores social issues such as the role of women in society and the legacies of the Khmer Rouge, grounding its narrative themes in a Cambodian context whilst expressing these through her dance vocabulary. Similarly, a rehearsal of a recent piece performed at the 2018 contemporary dance festival, called Living Cement ${ }^{i i}$, plays with ideas around the weight and vibrancy of tradition:

The piece starts with Belle entering in classical costume, complete with song book, then dances in a classical style, slowly turning 360 degrees on one foot, other leg bent back, foot flexed, arm postures using kbach but adapting these to fluidly hold the book to the audience to view. A gong sounds. Three students (two women, one man) enter upstage. Belle slowly walks with the grounded fluidity and bent knees of classical dance towards the students and beckons them as she moves to the singers and 
musicians sat at the side, passing the book to them before she sits. I feel this is a reflection of her own position as choreographer and teacher. The students sampeah to the small group as a mark of respect, but although their knees are bent, this is not in the classical dance manner. The three dancers then start to perform a series of synchronised movements in the way that they would at the start of every classical dance rehearsal. However, although using a traditional structure, with Cambodian music and singing, the dancers execute a varied set of contemporary movements. They do not stay on one spot as in classical rehearsals, but instead move as a group around the stage with speed, combining the curves of classical dance with its low centre of gravity, bent knees, S-bend in the spine, flexed feet and arms with the angular or straight lines of running, moving 360 degrees on the spot in postures at speed, upright jumping, and fluid modern dance movements. A sudden sway of the body with a sharp side snap of the head, as they follow the movement of their flexed back hands away and out from the eyes. Running of the hands along the arms, circles, reaching up, then to the ground. Arms wrapped around their own waists, then reaching up, their crossed hands flexed back as they lunge. They move into and out of classical sitting postures using planks, rolls, circular runs. At times they move together in tandem, at other times they do the same movements in different directions, slowly building to doing independent choreographies that then return to group formations.

The framing of the dance, alongside its choreographic vocabulary, situate contemporary Cambodian dance as part of an evolving, rather than static, tradition. It lives and morphs, whilst respecting what has come before. Videos show this type of work being performed in other artistic settings, such as Sa Sa Bassac, the leading contemporary art gallery in Phnom Penh, music concerts, and increasingly in government settings. Indeed, the contemporary dance festival in 2018 was organised by the Ministry of Culture and Fine Arts, signalling the increased legitimation of contemporary dance by the state. This style of contemporary dance therefore reworks the cultural association between dance and nationality in sites that are open to, and intervene in, cultural globalisation, including the state. The dancing body therefore multiplies the production of national culture through different choreographic combinations. However, whilst creatively reworking choreography occurs in sites that are embedded in cultural (and economic) globalisation, Belle also takes this movement vocabulary into everyday locations across Cambodia, something particularly evident in her screendances.

\section{Screendance and Everyday Space}

In his analysis of performance documentation among Cambodian visual arts practitioners, Nelson (2014) argues that the documentary imperative has emerged because artists now encounter performances through the internet, and there is an 
increased availability and everyday use of video technology. The Cambodian genre, simply called 'performance', is not concerned with a live encounter, and views photographs and videos as performances in and of themselves. Although Cambodian practitioners working in this vein have been exhibited internationally, Nelson (2014, 108) argues that they are more interested in the 'newness' or 'strangeness' of the genre, in its experimental possibilities, than in making works for foreign markets. 'Performance' is also distinct from existing performing art forms in Cambodia, such as dance, as it is not structured by codified traditions, but is instead a genre that has evolved from different impulses. In thinking about a group of videos on Belle's YouTube page that are a form of screendance, where the dance is created for the camera, it is worth highlighting that these works have emerged less from an engagement with international dance worlds and more from the cross-medium fluidity of Cambodia's art worlds. As Belle described:

I have a lot of friends who do contemporary work but with photographing, installation, painting, and costume design. It means my generation we start with dancing, arts, photos, and painting, we start something new that we call contemporary dance style. We have been talking and learn from each other also.

There exists a dialogue between different artists, medias and genres that facilitates the development of contemporary cultural expressions. However, Belle's work has to be seen in relation to Cambodian dance's codified history alongside these emergent forms of visual art practice.

Several screendances appear in multiple iterations on Belle's YouTube page, cut to different music or lengths. For instance, Her First Sunday iii, set in a partially demolished building, relays a story of relationship breakdown. The camera is placed on the floor with Belle aware of the spatialities of the frame that she can perform in and the architectural qualities that she can draw on (such as a doorway and a crumbling staircase, perhaps referencing a home). The effect is that the viewer feels as though they are spying on a personal moment of breakdown and violence, with movements such as clutching and circling her head in despair or falling as though she has been slapped round the face to the ground. One version uses a mournful instrumental that correlates with the destructive environment and choreography. Another uses a jazz recording of Silent Night with its references to peace and calm, creating an explicit contrast with the choreography, but a more hopeful ending as the lyrics of redemption coincide with her smoothing her hair, standing upright and walking away looking ahead, as though she is leaving this setting behind. There is a visible process of experimentation in operation that explores the creative possibilities for a work's aesthetic and meaning, rather than a commercial imperative, as Nelson (2014) suggests. 
The screendances are therefore more about personal motivations and interests, about creative exploration and collaboration as Belle indicated; 'I'm a dancer and I love to dance! Everywhere! New places always have meaning and something for us to learn and to feel.' Indeed, in relation to the extract below, Belle described how performing on Bokor Mountain in Kampot was a personal challenge that also strengthened the technical and emotional qualities of her dancing:

That is scary and high! The time I decide to dance on the mountain and it's stony and then you dance there and it's - phew!! And then you see, slowly, when you are scared of something you can do it. So this is a good memory for me! First, it's a challenge, two, it's the atmosphere, the view, the air, the nature - it really inspires you to be strong. And when you feel strong from here (inside), it makes your dance strong and then the is feeling there. You completely forget what you fear.

Such explorations further pluralise the impulses behind, and types of contemporary dance being created in Cambodia, but a key thing to note is the site-specificity of such work (see Norman 2010). These are personal responses to being in particular environments, and sometimes were created on visits where dance was not the original purpose. This is true of Rainbow Mountain, a screendance of Belle performing amid snow-covered mountainous when she went to New Zealand on the English Language Training for Officials (ELTO) programme. However, the screendances are usually made in different locations across Cambodia, such as dry rice fields in Banteay Meanchey Province, Ou Chher Teal Beach in Sihanoukville, and buildings in Phnom Penh (e.g. the White Building, an iconic site demolished in 2017 that re-housed artists after the Khmer Rouge):

Or Kun (trans: thank you) to Nature. ${ }^{i v}$ We hear the sound of crickets, cicadas and the wind. She reaches up to the sky, her hand comes down the centre of her body as she undulates, comes down to the ground, reaches out and touches the rocky outcrop she is stood on, pulls her hands up into a sampeah (thank you/prayer gesture) to her head. She kneels, moves into a flying posture, faces out into the wind towards the foggy view, stands, arm outstretched, looking out, like she has left something behind, turns around towards the camera but looks down, hands covering heart, slowly walks away.

The screendances harness landscapes for effect, and often explore feelings of being in or out of place. Their choreography responds to the settings, such as that feeling of wonder and strength inspired by nature. Similarly, a recent series of works choreographed by Belle and performed with/by other dancers explore ideas of shelter and the right to a home. Filmed in central Phnom Penh amid construction sites, old buildings, and performed even on a single brick, the films are wistful, longing, and speak to the capital's current rapid development and the displacements it is creating. In 
interview, Belle also described how contemporary dance entails leaning how to improvise and respond to different places, environments and atmospheres. Although this is part of what she saw as the form of contemporary dance, she also commented that in other countries performers do not always use a set stage, so being able to collaborate internationally entails having the facility to perform outside and the ability to respond to different stimuli.

Although there is, in part, an international impulse behind these works, there is also a concern with using contemporary dance to create dialogues on Cambodian social issues, to develop artistically and expressively, and to create 'contemporary Cambodian dance' as a genre. Through the visual aesthetics of the screendances, Belle also reworks the geographical spatialities of Cambodian dance in ways that are inclusive and responsive. Her expression draws upon classical dance, even as the body moves in and out of postures in ways that are more undulating or derived from other dance styles. Unlike the classical dance form that she was trained in, which is traditionally performed in elite spaces (the Royal Palace, Angkor's religious temples, and now the Chaktomuk Conference Hall), Belle's screendances use a contemporary reworking of traditional cultural forms to create a dialogue with the everyday spaces of Cambodian life. Even where her expressions draw more upon Euro-American modalities of movement, the screendances use choreography to respond to a Cambodian location. The filming style also emphasises Cambodia's landscapes. Although the framing often uses a conventional audience perspective (rather than cutting up or focusing on specific parts of the body), the landscape is very much part of the visual imagery, the scenography, as well as an active participant to which Belle responds. This also gives the screendances an art installation quality. Her work as a performer highlights how a new form of dance vocabulary, one forged through the encounter between cultural globalisation and cultural tradition, is used to create dialogic responses to specific everyday places. In the process, these sites help produce, and shape, contemporary Cambodian dance as a new national cultural form (see also Fowler and Jones 2007).

\section{Conclusion}

This chapter has explored how dance relates to the reconstitution of culture. Cambodian classical dance has historically been associated with nationality, and attempts to eradicate it under the Khmer Rouge has only intensified the relationship to national domains. However, some younger dancers such as Belle are creating alternative dance cultures that respect these traditions whilst also making them speak to Cambodian society today. In the process they rework the conventional image of the classical dancer, its modes and meanings of embodiment, and, by extension, the production of nationality. The chapter has explored the multiplicity of such creative practices and how they relate to specific spatial domains through an analysis of Belle's YouTube page. Her videos enable a consideration of how 'elite' dancers who have 
trained in a highly encultured form of movement are developing choreographic vocabularies across multiple cultural sites. In the process, the tight association between the dancing body and the national sphere loosens, enabling individual modes of expression to come to the fore. As a result, my analysis illustrates that not only is the nation is a performed and performative entity, but that its importance shifts according to the spaces of its enactment.

It is evident from the above that formal sites of national cultural reproduction (i.e. government settings) rarely appear on Belle's YouTube page, despite their importance in her daily life as a classical dance teacher at RUFA. In general, her page signifies how being (and earning a living as) a contemporary dancer occurs in varied sites outside these channels. However, her page also constructs an image of her contemporary practice as professional - a descriptor usually only associated with traditional Cambodian dance forms. Uploads of rehearsal footage, multiple variations and edits of her work, and the increasing emphasis on choreographing contemporary works for other dancers makes her creative process visible and signals the effort and expertise needed to create contemporary dance.

Examining Belle's choreography, and her role in Cambodia's dance worlds, also extends work that blurs neat divisions between 'elite' and 'everyday' forms of nationality (Edensor 2002; Antonsich 2016). By attending to different sites of praxis, it becomes evident that her work is particularly embedded in Euro-American forms of cultural globalisation. However, the impact of this on the reproduction and reworking of dance as a national cultural form varies. In some commercial settings, there is very little reference to Cambodian aesthetics or movement vocabularies. In others, the reference is gestural, as dance becomes used to promote specific products or companies. However, in sites where creative or personal expression comes to the fore, the training in, and use of, multiple dance vocabularies, enables her to explore specifically Cambodian topics, ideas or landscapes. Even screendance as a form emerges in Cambodia predominantly from cross-genre forms of experimentation that are specifically local. However, as she traverses these sites, Belle's contemporary movement lexicon articulates dance genres from different locations at home and abroad. These are never simply reiterated or 'copied' but instead harness dance as a process of creative cultural adaptation. In so doing, her practice undercuts the idea that the dancing body is simply a container for, or representative of, nationality. Rather, the dancing body is a vehicle that produces a dialogue between the past, the present, the site of performance, and multiple spaces of cross-cultural encounter.

\section{Author Bio}

Dr Amanda Rogers is an Associate Professor in Human Geography and the Geohumanities at Swansea University, UK. Her research currently focuses on post- 
conflict performance cultures in South East Asia, particularly in Cambodia, and their relationship to the re-production of nationality.

\section{Bibliography}

Albright, A. C. (1997), Choreographing Difference: The body and identity in contemporary dance, Middletown, USA: Wesleyan University Press.

Antonsich, M. (2016), 'The 'everyday' of banal nationalism - ordinary people's views on Italy and Italian', Political Geography, 54, 32-42.

Billig, M. (1995), Banal Nationalism, Thousand Oaks, California, USA and London, UK: Sage.

Brubaker, R. (1996), Nationalism Reframed: Nationhood and the national question in the new Europe, Cambridge: Cambridge University Press.

Burgess, Jean and Joshua Green. (2009), 'The entrepreneurial vlogger: participatory culture beyond the professional-amateur divide', in Pelle Snickars and Patrick Vonderau (eds), The YouTube Reader, Stockholm, Sweden: National Library of Sweden, pp. 89-107.

Cronin, Nessa and Till, Karen (2017) 'Embodied Geographies of the Nation: An Introduction', The Irish Review, 54, 1-7

Desmond, Jane C. (2017), 'Tracking the political economy of dance', in Rebekah J. Kowal, Gerald Siegmund, and Randy Martin (eds), The Oxford Handbook of Dance and Politics, Oxford, UK: Oxford University Press, pp.29-52.

Edensor, T. (2002), National Identity, Popular Culture and Everyday Life, Oxford: Berg.

Eggert, Amelia, (2011) 'A Cambodian Leitkultur: Cambodian concepts of art and culture', in Brigitta Hauser-Schäublin (ed), World Heritage Angkor and Beyond: Circumstances and Implications of UNESCO Listings in Cambodia, Göttingen: Universitätsverlag Göttingen, pp. 69-93.

Fowler, C. I. and R. Jones. (2007), 'Placing and scaling the nation', Environment and Planning D: Society and Space, 25 (2), 332-354. 
Grant, Catherine. (2016), 'Finding new ground: maintaining and transforming traditional music', in Katherine Brickell and Simon Springer (eds), The Handbook of Contemporary Cambodia, London, UK: Routledge, pp. 420-431.

Hawkins, H. (2017) Creativity, New York and Abingdon: Routledge.

Hobsbawm, E. and T. Ranger. (1983) The Invention of Tradition. Cambridge, UK: Cambridge University Press.

Hughes-Freeland, F. (2008), Embodied Communities: Dance traditions and change in Java, New York, USA and Oxford, UK: Berghan Books.

Hughes-Freeland, Felicia. (1999), 'Dance on film: strategy and serendipity', in Theresa Buckland (ed), Dance in the Field: Theory, methods and issues in dance ethnography, Basingstoke UK: Macmillan, pp.111-122.

Ingold, Tim and Elizabeth Hallam. (2007), 'Creativity and cultural improvisation: An introduction', in Elizabeth Hallam and Tim Ingold (eds), Creativity and Cultural Improvisation, Oxford UK and New York USA: Berg, pp.1-24.

Ingram, A. (2011), 'Making geopolitics otherwise: artistic interventions in global political space', Geographical Journal, 177 (3), 218-222.

Ingram, Alan. (2009), 'Art and the geopolitical: remapping security at Green Zone/Red Zone', in Alan Ingram and Klaus Dodds (eds), Spaces of Security and Insecurity: Geographies of the War on Terror, Farnham, UK: Ashgate Publishing, pp. 257-277.

Jones, R. and P. Merriman (2009), 'Hot, banal and everyday nationalism: bilingual road signs in Wales', Political Geography 28 (3), 164-173.

Kuhlke, Olaf. (2014), 'Dancing in foam city: Berlin and the viscous embodiment of German national identity at the Love Parade, 1989-2006', in Olaf Kuhlke and Adam Pine (eds), Global Movements: Dance, place and hybridity, Lanham Maryland, USA and London, UK: Rowman Littlefield Publishing, pp. 39-76.

Laurier, E. (2015), 'YouTube: fragments of a video-tropic atlas', Area, 48 (4), 488-495.

Liep, J. (2001), Locating Cultural Creativity, London: Pluto Press.

Longhurst, R. (2009), 'YouTube: a new space for birth?', Feminist Review, 93 (1), 46-63. 
Mayer, Tamar. (2004), 'Embodied Nationalisms', in Lynn A. Staeheli, Eleonore Kofman and Linda J. Peake (eds), Mapping Women, Making Politics: Feminist perspectives on political geography, New York and London: Routledge, pp.153-168.

McConnell, F. (2016), Rehearsing the State: The political practices of the Tibetan Government-in-Exile, Chichester, UK: Wiley-Blackwell.

Militz, E. and C. Schurr (2016), 'Affective nationalism: banalities of belonging in Azerbaijan', Political Geography, 54, 54-63.

Nelson, R. (2014), "Performance is Contemporary": Performance and its documentation in visual art in Cambodia', Udaya, Journal of Khmer Studies, 12, 95-143.

Norman, K. (2010), 'In and out of place: site-based screendance', The International Journal of Screendance, 1 (1), 13-20.

Peters, Kathrin and Andrea Seier. (2009), 'Home dance: mediacy and aesthetics of the self on YouTube', in Pelle Snickars and Patrick Vonderau (eds), The YouTube Reader, Stockholm, Sweden: National Library of Sweden, pp. 187-203.

Phim, T. S. and A, Thompson. (1999), Dance in Cambodia, Oxford: Oxford University Press.

Pine, Adam (2014), 'Salsa cosmopolitanism: situating the dancing body as part of the global cosmopolitan project', in Olaf Kuhlke and Adam Pine (eds), Global Movements: Dance, place and hybridity, Lanham Maryland, USA and London, UK: Rowman Littlefield Publishing, pp.121-140.

Pinkerton, A. D. and M. Benwell (2014), 'Rethinking popular geopolitics in the Falklands/Malvinas sovereignty dispute: creative diplomacy and citizen statecraft', Political Geography, 38, 12-22.

Plancke, C. (2017), 'Dance performances in post-genocide Rwanda: remaking identity, reconnecting present and past', Journal of Eastern African Studies, 11 (2), 329-346.

Plancke, C. (2016), 'Contemporary dynamics in Rwandan dances: identity, changing creativity and the globalisation of affect', Dance Research, 34 (2), 150-169.

Reed, S. A. (2010), Dance and the Nation: Performance, ritual and politics in Sri Lanka, Madison, Wisconsin USA: The University of Wisconsin Press. 
Richardson, L. (2017), 'Book review of Creativity by Harriet Hawkins', Cultural Geographies, 24 (4), 652-653.

Robertson, Roland. (1995), 'Glocalization: Time-space and homogeneityheterogeneity', in Mike Featherstone, Scott Lash and Roland Robertson (eds), Global Modernities, London UK: Sage, pp.25-44.

Rogers, A. (2018), 'Advancing the geographies of the performing arts: intercultural aesthetics, migratory mobility and geopolitics', Progress in Human Geography, 42 (4), 549-568.

Rogers, A. (2015), Performing Asian Transnationalisms: Theatre, identity and the geographies of performance, New York, USA and Abingdon, UK: Routledge.

Rogers, A. (2014), 'Thinking through intercultural spatialities on Imelda: A New Musical', The Journal of Intercultural Studies, 35 (1), 53-73.

Rogers, A. (2012), 'Emotional Geographies of Method Acting in Asian American Theater', Annals of the Association of American Geographers, 102 (2), 423-442.

Rosenberg, D. (2012), Screendance: Inscribing the ephemeral image, Oxford, UK: Oxford University Press.

Shapiro, Sophiline Cheam. (2010), 'Dancing Off-Centre', in Stephanie Burridge and Fred Frumberg (eds), Beyond the Apsara: Celebrating Dance in Cambodia, New Delhi, India and Abingdon, UK: Routledge, pp. 109-120.

Shapiro-Phim, T. (2008), 'Cambodia's "Seasons of Migration"', Dance Research Journal, 40 (2), 56-73.

Simpson, P. (2011), "So, as you can see ...': some reflections on the utility of video methodologies in the study of embodied practices', Area, 43 (3), 343-352.

Smith, Anthony D. (1995), Nations and Nationalism in a Global Era, Oxford: Blackwell Publishing.

Somdahl-Sands Katrinka and Paul C. Adams. (2014), 'Spaces of mediated performance', in Paul C. Adams, Jim Craine and Jason Dittmer (eds), The Ashgate Research Companion to Media Geography, Farnham, UK: Ashgate, pp. 347-361. 
Stephens, A. C. (2014), 'National feelings and the question of alternatives', Political Geography, 40, 61-63.

Tuchman-Rosta, C. (2018) Performance, Practice and Possibility: How large-sclae processes affect the bodily economy of Cambodia's classical dancers (Ph.D. Dissertation, UC Riverside).

Veal, C. (2016), 'A Choreographic Notebook: Methodological Developments in Qualitative Geographical Research', Cultural Geographies, 23 (2), 221-245.

Weber, C. (1998), 'Performative States', Millennium: Journal of International Studies 27 (1), 77-95.

\footnotetext{
'See Sodhachivy, C (2018) 'YouTube page', accessed 24 September 2018 at https://www.youtube.com/user/Chivybelle/videos.

ii See Sodhachivy, C (2018) 'Living Cement SilverBell', accessed 24 September 2018 at https://www.youtube.com/watch?v=-dxenFjv0c8/.

iii See Sodhachivy, C (2014) 'Copy of SBD Her First Sunday 2014', accessed 24 ${ }^{\text {th }}$ September 2018 at https://www.youtube.com/watch?v=gKDAILnxRs8.

iv See Sodhachivy, C (2013) 'Or Kun to the Nature', accessed 24 ${ }^{\text {th }}$ September 2018 at https://www.youtube.com/watch?v=-X4jCHWodUs.
} 